\section{Isolation forces the pace for cyclotron}

Now, after 22 years of haggling, South Africa has an accelerator of its own. This modern if slightly passé symbol of nationhood occupies more than 1,000 hectares of the flat sandy Pleistocene infill of the Western Cape, within sight of Table Mountain (on a clear day) and midway between two of the chief user groups at the Universities of Cape Town and Stellenbosch.

The machine, a variable-energy cyclotron capable of producing $200 \mathrm{MeV}$ protons now and comparable beams of heavy nuclei when the necessary ion sources are ready, is home-designed and home-built, although some components have been bought in from abroad. Director D. Reitmann and his sponsors, the CSIR, rightly boast that the cyclotron produced a proton beam when it was first switched on three months ago, but the former will not disclose the cost (R135 million so far), saying that the effect would be to "start all those arguments that the money should have been spent on schools or housing".

The long saga of the cyclotron typifies both the difficulties and the rewards of self-sufficiency engendered originally by pride and, latterly, by isolation. Eleven years, from 1966 to 1977 , is a long time for a feasibility study of a machine that is an elaboration, even if a good one, of a wellknown principle. The cost escalation, from R35 million over five years to four times as much over twice as long, is partly but not wholly attributable to inflation, financial crises and the usual inconstancy of governments.

The rewards are also plain. Reitmann points with pride to the home-made sections of the electronic racks that control the current in the coils that shape the magnetic field, as a function of radial distance, in the four sectoral magnets. The machine will be used by both nuclear physicists and physicians interested in

necessarily receive the proceeds.

So when will there be 'one man, one vote'? Significantly, none of the white parties fighting for election on 6 May appears to have raised this as an issue that must at some time be decided. To have done so would have been a recipe for losing votes. It seems to be widely agreed that the Progressive Party lost ground (so that it has yielded place as the largest parliamentary opposition to the Conservative Party) for hazarding the less radical suggestion that it would negotiate with the banned African National Congress (ANC), which organizes anti-apartheid activity, including bombings, from its base at Lusaka, the capital of Zambia.

So great are the electoral dangers of this forbidden question that it is unlikely to be mentioned even in the next election, due

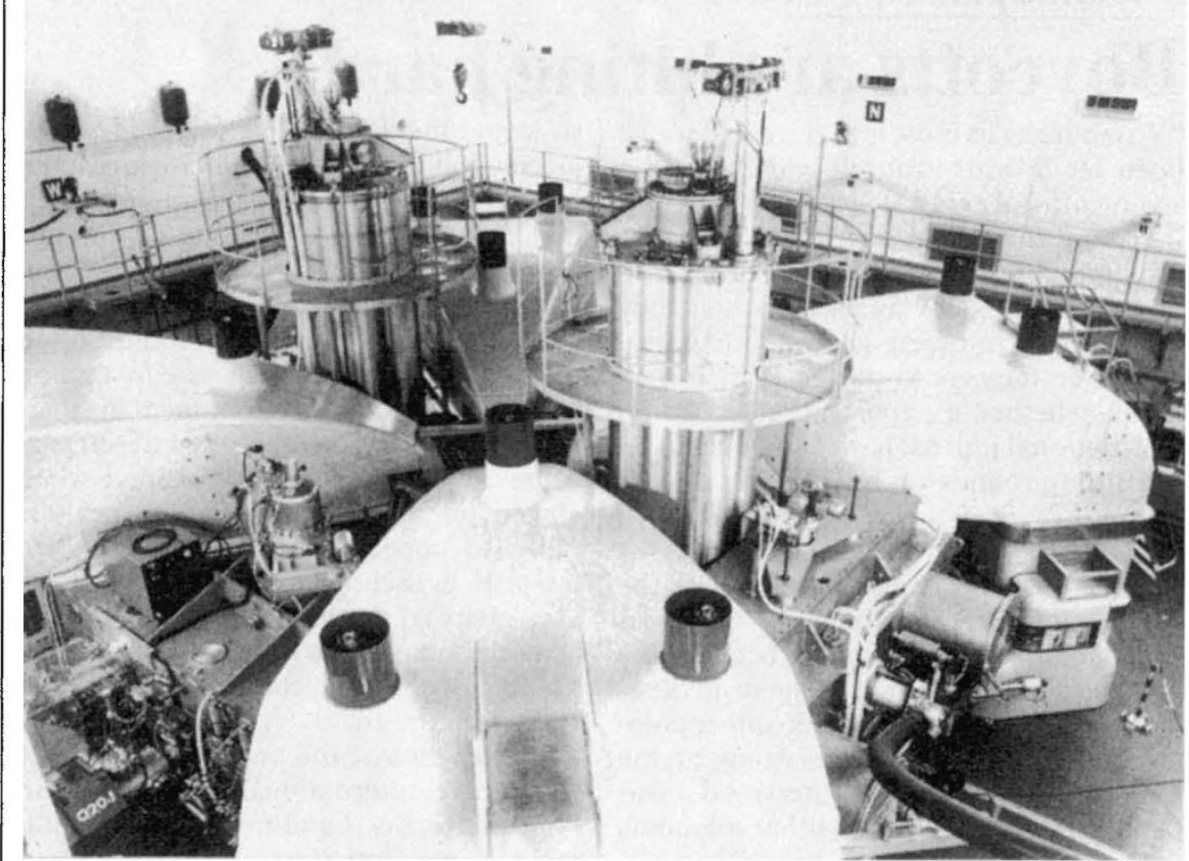

The cyclotron in the National Accelerator Centre - no route to international respectability.

particle beams for cancer therapy. There is also a facility for the production of short-lived isotopes. Reitman says that his cyclotron is matched only at a few laboratories around the world.

Who will use the machine? There are strong nuclear physics groups at nearby Cape Town and Stellenbosch and also at the University of the Witwatersrand. Time will be allocated by a users' committee, but the laboratory will provide all but the most experiment-specific ancillary equipment. Reitmann says that he would also welcome physicists from overseas "to these years". He says there have been some enquiries from US investigators, and suspects there would have been more if his colleagues had not been prevented from singing the praises of their machine at last December's cyclotron conference in Japan, from which they were banned. repay the hospitality we've received all

The medical case is less convincing. Some at a nearby medical school wonder whether the cost of the hospital will be justified by the treatment of just over 100 patients a year. A more practical difficulty is that nuclear physicists' interests may soon outgrow this machine, when an understandable feeling that the hospital should be decently amortized will make it a more durable incubus on the budget of the research foundation FRD, to which it will be transferred on 1 April next year.

All that could be different if, five years from now, South Africa had rejoined the international community, when international swapping of machine time might make it possible to sustain a diversified programme of academic research. As it looks now, Reitmann's splendid cyclotron will not be the price of entry to international collaboration but a monument to ambitions now frustrated.

two years from now (but which could be postponed if the government instead embarks on another round of constitutional change, the creation of a black council of state, for example).

Even liberal South African critics of apartheid do not seem to regard universal franchise as a necessary component of what the optimists call the "post-apartheid society". The white population, already a minority, knows that it will be an even smaller proportion of the total as the years go by. So people talk instead of elaborations of the tricameral parliament now in force, or the more ingenious electoral system devised by last year's indaba in Natal, which would ensure that no community's constitutional rights could be usurped.

One person, one vote, tomorrow would indeed be a recipe for disaster. The nonwhite majority has no political structure within which to organize its opinion. Moreover, with the present segregation of people's home addresses, it is unthinkable that the outcome of a free election could be determined on other than racial lines. The pity, at present, is that there is probably still a proportion (but shrinking) of non-whites willing to take part in the white political structure. A poll by The Sowetan in advance of the all-white election suggested that even Mr P.W. Botha's party could have counted on some support in Johannesburg's largest black township. The obvious hazard in the way of peaceful change is that non-white opinion will have hardened against participation in the postapartheid society before that comes into being. 